\title{
Detection of decreased glomerular filtration rate in intensive care units: serum cystatin $C$ versus serum creatinine
}

Pierre Delanaye ${ }^{1 *}$, Etienne Cavalier ${ }^{2}$, Jérôme Morel ${ }^{3}$, Manolie Mehdi ${ }^{4}$, Nicolas Maillard $^{4}$, Guillaume Claisse ${ }^{4}$, Bernard Lambermont ${ }^{5}$, Bernard E Dubois ${ }^{1}$, Pierre Damas ${ }^{6}$, Jean-Marie Krzesinski ${ }^{1}$, Alexandre Lautrette ${ }^{7}$ and Christophe Mariat ${ }^{4}$

\begin{abstract}
Background: Detecting impaired glomerular filtration rate (GFR) is important in intensive care units (ICU) in order to diagnose acute kidney injuries and adjust the dose of renally excreted drugs. Whether serum Cystatin C (SCysC) may better reflect glomerular filtration rate than serum creatinine $(\mathrm{SCr})$ in the context of intensive care medicine is uncertain.
\end{abstract}

Methods: We compared the performance of SCysC and SCr as biomarkers of GFR in 47 critically ill patients (median SOFA (Sepsis-related Organ Failure Assessment) score of 5) for whom GFR was measured by a reference method (urinary clearance of iohexol).

Results: Mean lohexol clearance averaged $96 \pm 54 \mathrm{~mL} / \mathrm{min}$ and was under $60 \mathrm{~mL} / \mathrm{min}$ in $28 \%$ of patients. Mean SCr and SCysC concentrations were $0.70 \pm 0.33 \mathrm{mg} / \mathrm{dL}$ and $1.26 \pm 0.61 \mathrm{mg} / \mathrm{L}$, respectively. Area under the ROC curve for a GFR threshold of $60 \mathrm{~mL} / \mathrm{min}$ was 0.799 and 0.942 for SCr and SCysC, respectively $(p=0.014)$.

Conclusions: We conclude that ScysC significantly outperfoms SCr for the detection of an impaired GFR in critically ill patients.

Trial registration: ClinicalTrials.gov: B7072006347

Keywords: Kidney failure, Cystatin C, Creatinine

\section{Background}

Detecting impaired glomerular filtration rate (GFR) is important in intensive care units (ICU) in order to (i) diagnose acute kidney injuries, (ii) prevent further degradation of renal function and (iii) adjust the dose of several renally excreted drugs. GFR estimation is usually based on serum creatinine ( $\mathrm{SCr}$ ) which is known to be a rather insensitive GFR biomarker. First, $\mathrm{SCr}$ is unable to reflect rapidly changing GFR, i.e. in a non steady state [1]. Moreover, SCr is not exclusively cleared by glomerular filtration but is also partially secreted by renal tubules. This well-known phenomenon may account for substantial GFR overestimation. Even more concerning

\footnotetext{
* Correspondence: pierre_delanaye@yahoo.fr

${ }^{1}$ Department of Nephrology-Dialysis, University of Liège, CHU Sart Tilman, Liège 4000, Belgium

Full list of author information is available at the end of the article
}

in the context of ICU is the dependency of SCr to muscular mass [2]. Critically ill patients are particularly prone to alteration in their muscle mass not only occurring during their stay in the ICU but also frequently already present at their admission to the ICU.

As compared to SCr, serum cystatin C (SCysC) is less dependent to muscle mass and is deemed as a more accurate GFR biomarker in different situations [3,4]. Several studies performed in critically ill patients have suggested the superiority of SCysC for the detection of a decreased GFR [5-9]. None of those studies has however compared the performance of SCysC against a reference method of GFR measurement. The real advantage of SCysC over SCr to estimate the so-called "true" GFR still remains to be demonstrated in the specific context of ICU.

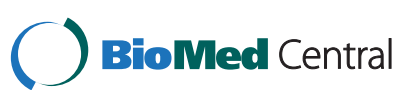


In this study, we directly assessed the true GFR of patients hospitalized in ICU by measuring their urinary clearance of iohexol [10]. The corresponding measured value was used as a gold standard to compare the relative performance of $\mathrm{SCr}$ and $\mathrm{SCysC}$ as GFR biomarkers in critically ill patients to detect decreased GFR. In this specific population, several studies have suggested that equations based on $\mathrm{SCr}$ are both inaccurate and imprecise [11-13]. We also study the ability of SCr-, ScysCbased and combined equations to estimate GFR in these ICU patients [14].

\section{Methods}

\section{Subjects}

Patients from 3 University hospitals (CHU Sart Tilman, University of Liège, Liège, Belgium; Hôpital Nord, University Jean Monnet, Saint Etienne, France and University of Clermont-Ferrand, Clermont-Ferrand, France), were included if they were older than 18 years, hemodynamically stable (mean arterial blood pressure $\geq$ $65 \mathrm{mmHg}$ with no modification in vaso-active drugs within the last 12 hours), under mechanical ventilation, with a urinary catheter, with a minimal diuresis of $400 \mathrm{~mL}$ in the last 6 hours, and with $\mathrm{SCr}<133 \mu \mathrm{mol} / \mathrm{L}$ $(1.5 \mathrm{mg} / \mathrm{dL})$. This value is arbitrary and recomended by the international guidelines of the K-DIGO (for "Kidney Disease: Improving Global Outcomes"). The main objective was to study the performance of $\mathrm{SCr}$ (and new biomarkers) to detect GFR below $60 \mathrm{~mL} / \mathrm{min}$. The sensitivity of SCr is clearly insufficient but its specificity is good. Therefore, we designed a study to try and address clinically relevant questions. In clinical practice and in the context of the detection of decreased GFR, there is few doubt that a given patient with $\mathrm{SCr}$ above $1.5 \mathrm{mg} / \mathrm{dL}$ suffered from kidney disease. Patients were not included in case of liver dysfunction (prothrombin time $<50 \%$ ), pregnancy, history of allergic reaction to iodine, active dysthyroidism and necessity of anti-inflammatory treatment by steroids. This study was approved by the Ethics Committee of CHU Sart Tilman (Liège, Belgium) and Hôpital Nord (Saint-Etienne, France). The Belgian number of this study is BE7072006347. The French number is 2009-010710-29. The necessary written informed consent was obtained for all patients involved in the study, including consent to publish.

\section{GFR measurement and biomarkers}

GFR was determined by urinary clearance of iohexol (Omnipaque $240 \mathrm{mgI} / \mathrm{mL}$, Amersham Health, New Jersey, USA). Two hours after the injection of 10 milliliters of iohexol, 4 clearances periods of one hour each were performed with plasma samples drawn at the beginning and the end of each period. Urine was separately collected for each period. Clearances periods for which the result was outside $\pm 20 \%$ of the mean clearance, or for which urine outflow was lower than 20 milliliters were not retained for the analysis. Iohexol clearance was determined as the mean of the different clearances periods. Iohexol samples were assayed by high performance liquid chromatography with high analytical performances [15]. External quality control was provided by Equalis (Uppsala, Sweden).

Table 1 GFR estimates ( $\mathrm{SCr}$ serum creatinine, SCysC serum cystatine C)

\begin{tabular}{|c|c|c|}
\hline Basis of equation and sex & $\mathrm{SCr}$ and SCysC values & Equation for estimating GFR \\
\hline MDRD & & $175 \times \mathrm{Scr}^{-1.154} \times$ age $^{-0.203} \times[0.742$ if female $]$ \\
\hline \multicolumn{3}{|l|}{ CKD-EPI SCr } \\
\hline \multirow[t]{2}{*}{ Female } & $\mathrm{SCr} \leq 0.7 \mathrm{mg} / \mathrm{dL}$ & $144 \times(\mathrm{Scr} / 0.7)^{-0.329} \times 0.993^{\mathrm{age}}$ \\
\hline & $\mathrm{SCr}>0.7 \mathrm{mg} / \mathrm{dL}$ & $144 \times(\mathrm{Scr} / 0.7)^{-1.209} \times 0.993^{\text {age }}$ \\
\hline \multirow[t]{2}{*}{ Male } & $\mathrm{SCr} \leq 0.9 \mathrm{mg} / \mathrm{dL}$ & $141 \times(\mathrm{Scr} / 0.9)^{-0.411} \times 0.993^{\mathrm{age}}$ \\
\hline & $\mathrm{SCr}>0.9 \mathrm{mg} / \mathrm{dL}$ & $141 \times(\mathrm{Scr} / 0.9)^{-1.209} \times 0.993^{\mathrm{age}}$ \\
\hline \multirow[t]{2}{*}{ CKD-EPI SCysC } & SCysC $\leq 0.8 \mathrm{mg} / \mathrm{L}$ & $133 \times(\text { SCysC } / 0,8)^{-0.499} \times 0.996^{\text {age }}[\times 0.932$ if female $]$ \\
\hline & SCysC $>0.8 \mathrm{mg} / \mathrm{L}$ & $133 \times(\text { Scys } / 0,8)^{-1.328} \times 0.996^{\text {age }}[\times 0.932$ if female $]$ \\
\hline \multicolumn{3}{|l|}{ CKD-EPI combined } \\
\hline \multirow[t]{4}{*}{ Female } & $\mathrm{SCr} \leq 0.7 \mathrm{mg} / \mathrm{dL}$ and SCysC $\leq 0.8 \mathrm{mg} / \mathrm{L}$ & $130 \times(\mathrm{Scr} / 0.7)^{-0.248} \times(\mathrm{SCysC} / 0.8)^{-0.375} \times 0.995^{\text {age }}$ \\
\hline & $\mathrm{SCr} \leq 0.7 \mathrm{mg} / \mathrm{dL}$ and SCysC $>0.8 \mathrm{mg} / \mathrm{L}$ & $130 \times(\mathrm{Scr} / 0.7)^{-0.248} \times(\mathrm{SCysC} / 0.8)^{-0.711} \times 0.995^{\mathrm{age}}$ \\
\hline & $\mathrm{SCr}>0.7 \mathrm{mg} / \mathrm{dL}$ and SCysC $\leq 0.8 \mathrm{mg} / \mathrm{L}$ & $130 \times(\mathrm{SCr} / 0.7)^{-0.601} \times(\mathrm{SCysC} / 0.8)^{-0.375} \times 0.995^{\text {age }}$ \\
\hline & $\mathrm{SCr}>0.7 \mathrm{mg} / \mathrm{dL}$ and SCysC $\geq 0.8 \mathrm{mg} / \mathrm{L}$ & $130 \times(\mathrm{SCr} / 0.7)^{-0.601} \times(\mathrm{SCysC} / 0.8)^{-0.711} \times 0.995^{\text {age }}$ \\
\hline \multirow[t]{4}{*}{ Male } & $\mathrm{SCr} \leq 0.9 \mathrm{mg} / \mathrm{dL}$ and $\mathrm{SCysC} \leq 0.8 \mathrm{mg} / \mathrm{L}$ & $135 \times(\mathrm{SCr} / 0.9)^{-0.207} \times(\mathrm{SCysC} / 0.8)^{-0.375} \times 0.995^{\text {age }}$ \\
\hline & $\mathrm{SCr} \leq 0.9 \mathrm{mg} / \mathrm{dL}$ and SCysC $>0.8 \mathrm{mg} / \mathrm{L}$ & $135 \times(\mathrm{SCr} / 0.9)^{-0.207} \times(\mathrm{SCysC} / 0.8)^{-0.711} \times 0.995^{\text {age }}$ \\
\hline & $\mathrm{SCr}>0.9 \mathrm{mg} / \mathrm{dL}$ and SCysC $\leq 0.8 \mathrm{mg} / \mathrm{L}$ & $135 \times(\mathrm{SCr} / 0.9)^{-0.601} \times(\mathrm{SCysC} / 0.8)^{-0.375} \times 0.995^{\text {age }}$ \\
\hline & $\mathrm{SCr}>0.9 \mathrm{mg} / \mathrm{dL}$ and SCysC $>0.8 \mathrm{mg} / \mathrm{L}$ & $135 \times(\mathrm{SCr} / 0.7)^{-0.601} \times(\mathrm{SCysC} / 0.8)^{-0.711} \times 0.995^{\text {age }}$ \\
\hline
\end{tabular}


Table 2 Clinical and biological characteristics of the population

\begin{tabular}{cc}
\hline Age (years) & $62 \pm 17$ \\
Gender & 25 women/ 22 men \\
Weight $(\mathrm{kg})$ & $81 \pm 24$ \\
Height $(\mathrm{cm})$ & $168 \pm 10$ \\
Body mass index $\left(\mathrm{kg} / \mathrm{m}^{2}\right)$ & $29 \pm 8$ \\
Cause of admission & Sepsis (39\%) \\
& Neurologic diseases \\
& $(32 \%)$ \\
& Trauma (16\%) \\
& Myocardial infarction \\
& $(5 \%)$ \\
SOFA (Sepsis-related Organ Failure Assessment) & $5[4 ; 9]$ \\
score & $96 \pm 54$ \\
GFR (mL/min) & $0.70 \pm 0.33$ \\
Serum creatinine (mg/dL) & $1.26 \pm 0.61$ \\
Serum cystatin C (mg/L)
\end{tabular}

SCr was measured by the IDMS traceable enzymatic method (Roche Diagnostics, Mannheim, Germany) on Modular apparatus. SCysC was measured by a particleenhanced nephelometric immunoassay on the BNII nephelometer (Siemens Healthcare Diagnostics, Marburg, Germany). The assay was calibrated against the international certified reference material ERM-DA471/ IFCC for cystatin C. Both $\mathrm{SCr}$ and $\mathrm{SCysC}$ were sampled at the beginning of the first clearance period, kept at $-80^{\circ} \mathrm{C}$ to be centrally processed at the University of Liège (Department of Clinical Chemistry, ISO 15189 Standard-accredited laboratory).

We studied the performance of the most widely used $\mathrm{SCr}-$ and ScysC-based equations, i.e. the Modification of Diet in Renal Disease (MDRD) [16] and the CKDEpidemiology Collaboration (CKD-EPI) equations (Table 1) [14].

\section{Statistics}

Data were expressed as mean \pm standard deviation (SD) when distribution was normal and as median and
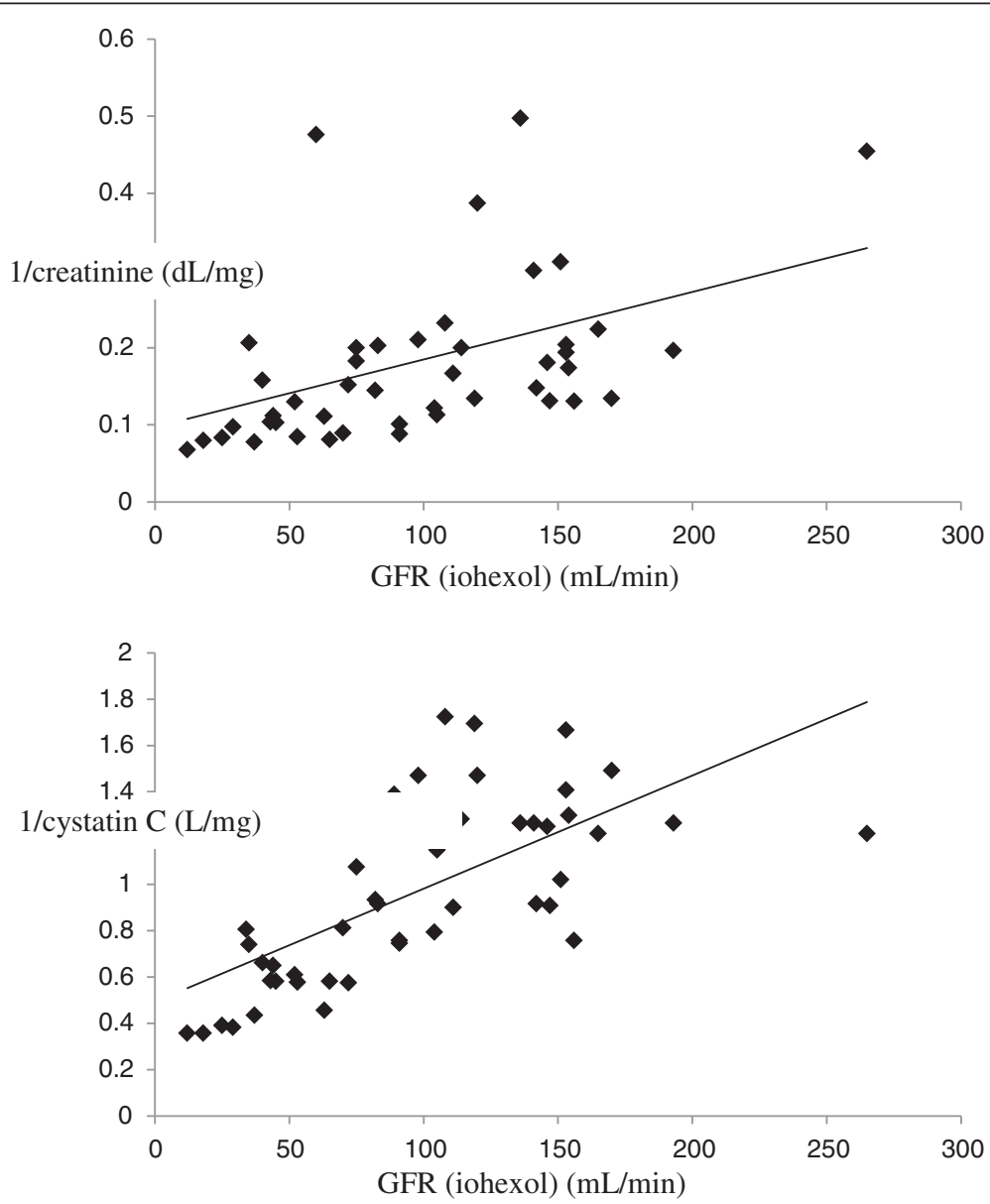

Figure 1 Correlations between the inverse of creatinine and GFR (upper) $(y=0,09024+0,0009156 x)$ and the inverse of cystatin C and GFR (lower) $(y=0,4939+0,004871 \times)$. 


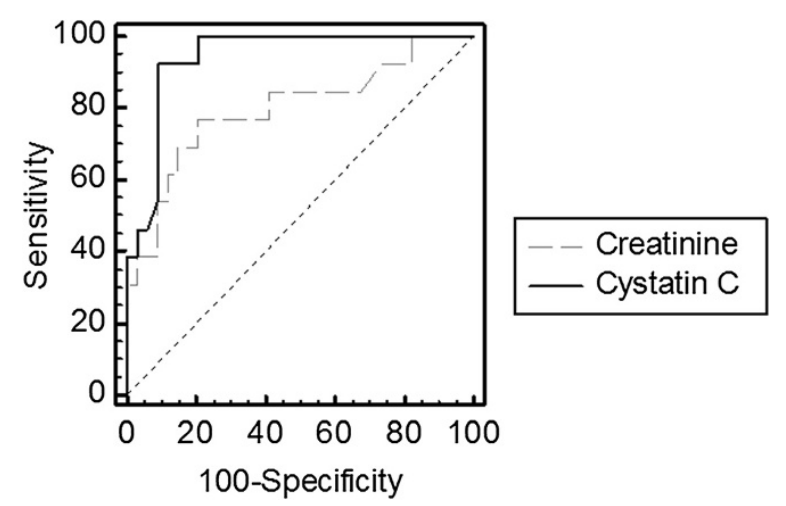

Figure 2 ROC curves analysis for cystatin C $(-)(A \cup C=0.942)$ and creatinine $(-\longrightarrow)$ (AUC $=0.799)$ to detect GFR under $60 \mathrm{~mL} / \mathrm{min}(p=0.014)$.

interquartile range [IQR] if not. Performance of $\mathrm{SCr}$ and $\mathrm{SCysC}$ was evaluated by analyzing their respective correlation with iohexol clearance and by calculating the area under the ROC curves to detect an iohexol clearance below $60 \mathrm{~mL} / \mathrm{min}$. Statistics were performed using MedCalc ${ }^{\circ}$ (MedCalc Software, Mariakerke, Belgium). The predictive performance of the GFR estimates was assessed with the following parameters:

- Absolute bias, defined as the mean difference between estimating GFR (eGFR) and measured GFR (mGFR), a negative value meaning that eGFR underestimates true GFR.

- Precision, evaluated by the standard deviation of the mean difference between eGFR and mGFR

- Accuracy, defined as the proportion of eGFR values within $+/-30 \%$ of the mGFR.

Comparison of precision and accuracy were performed using F-test and McNemar paired test. A p value $<0.05$ was considered as statistically significant.

\section{Results}

Fifty-one patients were included. All patients were Caucasian. Four patients were retrospectively excluded due to technical errors in the clearance procedure. According to our criteria, $86 \%$ of clearance periods have been considered. Mean GFR value in our population was $98 \pm 56 \mathrm{~mL} / \mathrm{min}$.
Characteristics of the 47 patients retained for the analysis are presented in Table 2. While mean SCr was low ( $0.7 \pm$ $0.33 \mathrm{mg} / \mathrm{dL}$ ), $28 \%$ of patients had an iohexol clearance below $60 \mathrm{~mL} / \mathrm{min} / 1.73 \mathrm{~m}^{2}$. The reciprocal of SCysC better correlated to iohexol clearance than the reciprocal of $\mathrm{SCr}$ $(r=0.667$ and $r=0.499$, respectively) (Figure 1). This difference did not reach the statistical significance. SCysC was however significantly superior to $\mathrm{SCr}$ to discriminate patients with an iohexol clearance above or below the threshold of $60 \mathrm{~mL} / \mathrm{min}$ (AUC ROC of 0.942 and 0.799, respectively, $\mathrm{p}=0.014$ ) (Figure 2 ).

The global performances of estimating GFR were very poor (Table 3). The best accuracy within 30\% was observed both for the CKD EPI SCr and combined equations (59 and 62\%, respectivelly). Performance of the MDRD was significantly worse (40\%).

\section{Discussion}

$\mathrm{SCysC}$ is recognized to be far less influenced by muscular mass than $\mathrm{SCr}$ [4]. Not surprinsingly, $\mathrm{SCysC}$ has been validated as a superior GFR biomarker to detect chronic kidney disease (defined as GFR below $60 \mathrm{~mL} / \mathrm{min} / 1.73 \mathrm{~m}^{2}$ ) in several specific populations with decreased or abnormal muscular mass like in the elderly, cirrhotic patients, renal transplant patients, and patients suffering from anorexia nervosa $[3,13,17]$. Herein, we extend this notion to critically ill patients. Numerous previous studies performed in severely ill patients (not necessarily hospitalized in ICU) have suggested the better performance of $\mathrm{SCysC}$ for detecting AKI $[5,6]$. However since most of those studies did not provide a reference GFR measurement against which $\mathrm{SCr}$ and $\mathrm{SCysC}$ could be thoroughly compared, the real added value of SCysC as a marker of GFR has remained partly speculative [6]. Among all these studies, only two of them realized after cardiac surgery have measured GFR by a reference method (iohexol or ${ }^{51} \mathrm{Cr}$-EDTA) and showed superior performance of cystatin C $[18,19]$. Focusing specifically on critically ill patients, Le Bricon et al. measured GFR by a reference method $\left({ }^{51} \mathrm{Cr}\right.$-EDTA $)$ and showed a better correlation between 1/cystatin $C$ and GFR than between 1/creatinine and GFR $(r=0.755$ versus $r=0.686)$. The authors also demonstrated a better sensitivity-specificity of cystatin $\mathrm{C}$ to detect impaired GFR [20]. However, the number of patients included in this study was very limited $(n=15)$. In addition, in this study, the ${ }^{51} \mathrm{Cr}$-EDTA clearance was

Table 3 Predictive performances of the MDRD, CKD-EPI SCr, CKD-EPI SCysC, and combined equations in ICU patients

\begin{tabular}{lccc}
\hline GFR estimates & Bias (mL/min) & Absolute Precision mL/min & Accuracy $\mathbf{3 0 \%}$ \\
\hline MDRD & +35 & 70 & 40 \\
CKD-EPI & +1 & 37 & $60^{*}$ \\
CKD-EPI Scyst & -26 & 36 & 53 \\
CKD-EPI combined & -12 & 35 & 62 \\
\hline
\end{tabular}

*: $p<0.05$ versus MDRD study equation. 
carried out according to a plasmatic method which is not necessarily as accurate as the urinary method especially in patients with variable and unpredictable volumes of distribution [21].

As compared to the aforementioned studies, the major strength of ours is the use of a very rigorous method of GFR measurement in a selected population of stable but critically ill patients. In this regard, our results do really reflect the physiological performances of the two biomarkers against the "true" GFR, a parameter that is particularly uneasy to approach in the context of ICU. Thus, our data strongly suggest the superiority of $\mathrm{SCysC}$ over $\mathrm{SCr}$ in critically ill patients.

However, even if ScysC is better than $\mathrm{SCr}$ to detect decreased GFR, the accuracy, and especially the precision, of ScysC-based or combined equations to estimate GFR is clearly insufficient and have no added value compared to SCr-based equations. This result is explained by the different characteristics of the subject compared to the populations analyzed in the CKD-EPI cohort (chronic versus acute disease, decreased muscular mass etc).

There are however several limitations to our study. First, we enrolled prevalent patients and our study is purely cross-sectional. Although patients with relatively low $\mathrm{SCr}$ have been included in our study, we cannot exclude the hypothesis that patient with pre-existing chronic kidney disease, have been included. Second, our sample remains relatively limited and only includes patients with $\mathrm{SCr}<$ $133 \mu \mathrm{mol} / \mathrm{L}(1.5 \mathrm{mg} / \mathrm{dL})$. Our results must be confirmed in a larger cohort and in patients with a larger range of $\mathrm{SCr}$ and GFR. Lastly, cystatin C concentration is also influenced by non-GFR factors. While we took into account some confounding factors (steroids and dysthyroidism), others factors may have played a role $[22,23]$. Finally, the better performance of ScysC could potentially be due to a quicker reach of its steady state when GFR rapidly changes. However, this point remains purely speculative and cannot be addressed in our cross- sectional designed study.

\section{Conclusion}

In conclusion, $\mathrm{SCysC}$ performs significantly better than $\mathrm{SCr}$ in order to detect critically ill patients with measured GFR below $60 \mathrm{ml} / \mathrm{min}$. More generally, we believe that SCysC is a more valid GFR biomarker than $\mathrm{SCr}$ in ICU and as such, might be evaluated as part of the AKI definition/classification in replacement of SCr.

\section{Key messages}

- High percentage of patients hospitalized in intensive care units has normal creatinine concentration but decreased glomerular filtration rate.
- Cystatin $C$ is better than creatinine to detect measured glomerular filtration rate less than $60 \mathrm{~mL} /$ $\mathrm{min} / 1.73 \mathrm{~m}^{2}$.

- All estimating equations lack of precision to estimate GFR.

\section{Abbreviations}

GFR: Glomerular filtration rate; ICU: Intensive care unit; SCr: Serum creatinine; SCysC: Serum cystatin C; SOFA: (Sepsis-related Organ Failure Assessment).

\section{Competing interest}

The authors declare that they have no competing interest.

\section{Authors' contribution}

PD, EC, CM are the principal investigators. PD and CM have been involved in drafting the manuscript. EC is the Biochemist who measured serum creatinine and cystatin C. JM, MM, NM, GC, BL, BED, PDa, AL and CM are the clinicians who included the patients in the different centers. They all participated to the acquisition of the data. BL, PDa, JMK, AL and CM have critically corrected the manuscript as Chief of the Department of medical intensive care (Liège), general intensive care (Liège), Nephrology (Liège), general intensive care (Clermont Ferrant) and nephrological intensive care (Saint-Etienne), respectively. All authors read and approved the final manuscript.

\section{Acknowledgement}

This work has been supported by a grant from the Guy Mathot and Léon Fredericq foundations.

\section{Author details}

${ }^{1}$ Department of Nephrology-Dialysis, University of Liège, CHU Sart Tilman, Liège 4000, Belgium. ${ }^{2}$ Department of Clinical Chemistry, University of Liège, CHU Sart Tilman, Belgium. ${ }^{3}$ Department of General Intensive care, University Jean Monnet, Hôpital Nord, Saint-Etienne, France. ${ }^{4}$ Department of Nephrological Intensive Care, University Jean Monnet, Hôpital Nord, Saint-Etienne, France. ${ }^{5}$ Department of Medical Intensive Care, University of Liège, CHU Sart Tilman, Belgium. 'Department of General Intensive care, University of Liège, CHU Sart Tilman, Belgium. ${ }^{7}$ Department of Intensive Care Unit, University of Clermont-Ferrand, Clermont-Ferrand, France.

Received: 8 May 2013 Accepted: 6 January 2014

Published: 13 January 2014

\section{References}

1. Chen S: Retooling the creatinine clearance equation to estimate kinetic GFR when the plasma creatinine is changing acutely. J Am Soc Nephrol 2013, 24:877-888.

2. Perrone RD, Madias NE, Levey AS: Serum creatinine as an index of renal function: new insights into old concepts. Clin Chem 1992, 38:1933-1953.

3. Delanaye P, Cavalier E, Radermecker RP, Paquot N, Depas G, Chapelle JP, Scheen AJ, Krzesinski JM: Cystatin C or creatinine for detection of stage 3 chronic kidney disease in anorexia nervosa. Nephron Clin Pract 2008, 110:c158-c163.

4. Vinge E, Lindergard B, Nilsson-Ehle P, Grubb A: Relationships among serum cystatin C, serum creatinine, lean tissue mass and glomerular filtration rate in healthy adults. Scand J Clin Lab Invest 1999, 59:587-592.

5. Bagshaw SM, Bellomo R: Cystatin C in acute kidney injury. Curr Opin Crit Care 2010, 16:533-539.

6. Zhang Z, Lu B, Sheng X, Jin N: Cystatin C in prediction of acute kidney injury: a systemic review and meta-analysis. Am J Kidney Dis 2011, 58:356-365.

7. Delanaye P, Lambermont B, Chapelle JP, Gielen J, Gerard P, Rorive G: Plasmatic cystatin $\mathrm{C}$ for the estimation of glomerular filtration rate in intensive care units. Intensive Care Med 2004, 30:980-983.

8. Herget-Rosenthal S, Marggraf G, Husing J, Goring F, Pietruck F, Janssen O, Philipp T, Kribben A: Early detection of acute renal failure by serum cystatin C. Kidney Int 2004, 66:1115-1122.

9. Nejat M, Pickering JW, Walker RJ, Endre ZH: Rapid detection of acute kidney injury by plasma cystatin $\mathrm{C}$ in the intensive care unit. Nephrol Dial Transplant 2010, 25:3283-3289. 
10. Erley CM, Bader BD, Berger ED, Vochazer A, Jorzik JJ, Dietz K, Risler T: Plasma clearance of iodine contrast media as a measure of glomerular filtration rate in critically ill patients. Crit Care Med 2001, 29:1544-1550.

11. Hoste EA, Damen J, Vanholder RC, Lameire NH, Delanghe JR, Van den Hauwe K, Colardyn FA: Assessment of renal function in recently admitted critically ill patients with normal serum creatinine. Nephrol Dial Transplant 2005, 20:747-753.

12. Poggio ED, Nef PC, Wang X, Greene T, Van Lente F, Dennis WW, Hall PM: Performance of the cockcroft-gault and modification of diet in renal disease equations in estimating GFR in ill hospitalized patients. Am J Kidney Dis 2005, 46:242-252.

13. Segarra A, de la Torre J, Ramos N, Quiroz A, Garjau M, Torres I, Azancot MA, Lopez M, Sobrado A: Assessing glomerular filtration rate in hospitalized patients: a comparison between CKD-EPI and four cystatin C-based equations. Clin J Am Soc Nephrol 2011, 6:2411-2420.

14. Inker LA, Schmid CH, Tighiouart H, Eckfeldt JH, Feldman Hl, Greene T, Kusek JW, Manzi J, Van LF, Zhang YL, et al: Estimating glomerular filtration rate from serum creatinine and cystatin C. N Engl J Med 2012, 367:20-29.

15. Cavalier E, Rozet E, Dubois N, Charlier C, Hubert P, Chapelle JP, Krzesinski $J M$, Delanaye P: Performance of iohexol determination in serum and urine by HPLC: validation, risk and uncertainty assessment. Clin Chim Acta 2008, 396:80-85.

16. Levey AS, Coresh J, Greene T, Stevens LA, Zhang YL, Hendriksen S, Kusek JW, Van Lente F: Using standardized serum creatinine values in the modification of diet in renal disease study equation for estimating glomerular filtration rate. Ann Intern Med 2006, 145:247-254.

17. Masson I, Maillard N, Tack I, Thibaudin L, Dubourg L, Delanaye P, Cavalier E, Bonneau C, Kamar N, Morelon E, et al: GFR estimation using standardized cystatin C in kidney transplant recipients. Am J Kidney Dis 2013, 61:279-284.

18. Bronden B, Eyjolfsson A, Blomquist S, Dardashti A, Ederoth P, Bjursten H: Evaluation of cystatin $C$ with iohexol clearance in cardiac surgery. Acta Anaesthesio/ Scand 2011, 55:196-202.

19. Wang QP, Gu JW, Zhan XH, Li H, Luo XH: Assessment of glomerular filtration rate by serum cystatin $\mathrm{C}$ in patients undergoing coronary artery bypass grafting. Ann Clin Biochem 2009, 46:495-500.

20. Le Bricon T, Leblanc I, Benlakehal M, Gay-Bellile C, Erlich D, Boudaoud S: Evaluation of renal function in intensive care: plasma cystatin $C$ vs. creatinine and derived glomerular filtration rate estimates. Clin Chem Lab Med 2005, 43:953-957.

21. Skluzacek PA, Szewc RG, Nolan CR III, Riley DJ, Lee S, Pergola PE: Prediction of GFR in liver transplant candidates. Am J Kidney Dis 2003, 42:1169-1176.

22. Knight EL, Verhave JC, Spiegelman D, Hillege HL, de Zeeuw D, Curhan GC, de Jong PE: Factors influencing serum cystatin $C$ levels other than renal function and the impact on renal function measurement. Kidney Int 2004, 65:1416-1421.

23. Seronie-Vivien S, Delanaye P, Pieroni L, Mariat C, Froissart M, Cristol JP: Cystatin C: current position and future prospects. Clin Chem Lab Med 2008, 46:1664-1686.

doi:10.1186/1471-2369-15-9

Cite this article as: Delanaye et al:: Detection of decreased glomerular filtration rate in intensive care units: serum cystatin $C$ versus serum creatinine. BMC Nephrology 2014 15:9.

\section{Submit your next manuscript to BioMed Central and take full advantage of:}

- Convenient online submission

- Thorough peer review

- No space constraints or color figure charges

- Immediate publication on acceptance

- Inclusion in PubMed, CAS, Scopus and Google Scholar

- Research which is freely available for redistribution

Submit your manuscript at www.biomedcentral.com/submit 